\title{
Challenges of Coverage Policy Development for Next-Generation Tumor Sequencing Panels: Experts and Payers Weigh In
}

\author{
Julia R. Trosman, PhD ${ }^{\mathrm{a}, \mathrm{b}, \mathrm{c}}$; Christine B. Weldon, $\mathrm{MBA}^{\mathrm{a}, \mathrm{b}, \mathrm{c}}$; R. Kate Kelley, MD ${ }^{\mathrm{a}, \mathrm{d}}$; and \\ Kathryn A. Phillips, PhDa,e
}

\begin{abstract}
Background: Next-generation tumor sequencing (NGTS) panels, which include multiple established and novel targets across cancers, are emerging in oncology practice, but lack formal positive coverage by US payers. Lack of coverage may impact access and adoption. This study identified challenges of NGTS coverage by private payers. Methods: We conducted semi-structured interviews with 14 NGTS experts on potential NGTS benefits, and with 10 major payers, representing more than 125,000,000 enrollees, on NGTS coverage considerations. We used the framework approach of qualitative research for study design and thematic analyses and simple frequencies to further describe findings. Results: All interviewed payers see potential NGTS benefits, but all noted challenges to formal coverage: $80 \%$ state that inherent features of NGTS do not fit the medical necessity definition required for coverage, $70 \%$ view NGTS as a bundle of targets versus comprehensive tumor characterization and may evaluate each target individually, and 70\% express skepticism regarding new evidence methods proposed for NGTS. Fifty percent of payers expressed sufficient concerns about NGTS adoption and implementation that will preclude their ability to issue positive coverage policies. Conclusions: Payers perceive that NGTS holds significant promise but, in its current form, poses disruptive challenges to coverage policy frameworks. Proactive multidisciplinary efforts to define the direction for NGTS development, evidence generation, and incorporation into coverage policy are necessary to realize its promise and provide patient access. This study contributes to current literature, as possibly the first study to directly interview US payers on NGTS coverage and reimbursement. (J Natl Compr Canc Netw 2015;13:311-318)
\end{abstract}

\section{Background}

Precision oncology, the use of genomic and molecular markers to tailor treatment for individual patients, has achieved landmark advances illustrating the potential to transform cancer care and improve patient outcomes. ${ }^{1-4}$ One of the most important technological advances enabling precision oncology is next-generation tumor sequencing (NGTS), the use of massively parallel technologies to simultaneously examine large numbers of genetic tumor alterations. ${ }^{5-10}$ NGTS offers a host of advantages, including unprecedented accuracy and speed. ${ }^{11-14}$ Although early in its evolution, it has crossed over to clinical practice, ${ }^{13,15-18}$ enabled by the recent sharp

From aUCSF Center for Translational and Policy Research on Personalized Medicine (TRANSPERS), Department of Clinical Pharmacy, University of California, San Francisco (UCSF), San Francisco, California; ${ }^{\mathrm{b} C e n t e r}$ for Business Models in Healthcare, Chicago Illinois; 'Feinberg School of Medicine, Northwestern University, Chicago, Illinois; 'Department of Medicine, Division of Hematology/Oncology, UCSF, San Francisco, California; and eHelen Diller Family Comprehensive Cancer Center at UCSF, San Francisco, California.

Submitted May 12, 2014; accepted for publication August 4, 2014. Dr. Trosman and Ms. Weldon have disclosed that they are a consultant for Foundation Medicine. Dr. Kelley has disclosed that she has no financial interests, arrangements, affiliations, or commercial interests with the manufacturers of any products discussed in this article or their decline in costs ${ }^{19-22}$ and the increasingly rapid return of results. ${ }^{13,14,16}$ The arrival of NGTS in clinical care is also signaled by its inclusion in some oncology guidelines, ${ }^{23,24}$ the emergence of commercial offerings, ${ }^{25-27}$ and its heightened visibility to the general public. ${ }^{28-31}$

With the emergence of NGTS in clinical practice, insurance coverage and reimbursement for NGTS are becoming forefront issues: most US payers have not issued formal positive coverage policies, and some recently issued noncoverage decisions. ${ }^{32-35}$ Although it is possible to receive reimbursement for NGTS, 36,37 the lack of formal coverage causes payment uncertainty and variability, and limits patient access. ${ }^{38-41}$

competitors. Dr. Phillips has disclosed that she has received honorarium for a speaking engagement from Life Technologies. This work was supported by a grant from the National Human Genome Research Institute (R01HG007063), and by a grant from UCSF Mount Zion Health Fund and Helen Diller Family Comprehensive Cancer Center at UCSF (5P30CA082013-15). Additionally, the work of Dr. Trosman, Ms. Weldon, and Dr. Phillips for data collection was partially supported by funding from Life Technologies. Funding entities had no role in the design of the study, the collection and interpretation of the data, the writing of the manuscript, the manuscript approval, or the decision to submit the manuscript for publication.

Correspondence: Julia R. Trosman, PhD, 2705 West Agatite Avenue, Suite 200, Chicago, IL 60625. E-mail: trosman@centerforbusinessmodels.com 
Trosman et al

Our exploratory study identified payers' challenges to establishing formal coverage for NGTS. We focused on private payers, who represent important stakeholders in US reimbursement, covering more than two-thirds of the US insured population..$^{42}$ Understanding insurance coverage considerations for NGTS is vital for all oncology stakeholders, including oncologists, pathologists, laboratories, patients, and researchers.

Our study contributes to current literature, representing possibly the first study to directly interview US payers on NGTS reimbursement. We interviewed senior executives at 7 of the top 10 largest US health plans and at 4 regional plans, with a combined membership representing more than 125,000,000 enrollees. This builds on our previous studies involving private payers on coverage and reimbursement of precision oncology, using similar methods. ${ }^{43-47}$

\section{Methods}

This interview study was conducted with approval from the University of California, San Francisco's (UCSF's) Institutional Review Board (IRB). We used the framework approach of qualitative research $^{48}$ to guide design and data analyses. These methods are effective in exploratory studies on novel topics, ${ }^{49,50}$ and we and others have previously used these methods for examining coverage and adoption challenges of precision medicine. ${ }^{43-47,51-56}$

Study participants were identified using purposive sampling ${ }^{50}$ and recruited through the UCSF's Center For Translational and Policy Research on Personalized Medicine (TRANSPERS) Advisory Board. We developed 2 cohorts for this study: the expert cohort (individuals who are experts in clinical and research topics related to NGTS) and the payer cohort (senior executives from large national plans and regional plans, responsible for coverage decisions and evidence evaluation).

The semi-structured interviews were conducted from April through August 2013. We first conducted expert interviews to identify salient NGTS features and potential benefits. We then interviewed payers to examine how these features and potential benefits are considered for coverage decisions (a summary of the interview questions is provided in Table 1 , available online, in this article, at JNCCN.org). All interviews were conducted by telephone, lasted 30 to
45 minutes, and were recorded and transcribed. The interview questions were sent to participants before the interview. Two investigators independently analyzed the interviews, resolving disagreement through discussion and consensus. We used simple frequencies to further describe the coded data where relevant.

We focused the interviews on NGTS panels, sequencing assays interrogating tens to hundreds of tumor genetic and molecular targets of varying clinical significance. The topics of germline genetic testing, sequencing technical and platform issues, and comparison of specific NGTS products were excluded. We described conventional molecular diagnostics as "single test/single result" assays, because they return a single biomarker result or a single value, such as cancer recurrence scores. Examples of NGTS panels and conventional tests were provided, but specific tests were not discussed.

\section{Results}

\section{Participant Characteristics}

The expert cohort included 14 individuals-7 pathologists and 7 oncologists from $6 \mathrm{NCI}$-designated cancer centers-with firsthand knowledge and experience of NGTS technology, research applications, and/or clinical use. The payer cohort included 10 senior executives responsible for coverage policy from 7 of the 10 largest national plans and 4 regional plans. The experts represent leading US cancer institutions, and the payers cover more than 125,000,000 enrollees combined. Participants and organizations are not named here to protect anonymity. Our cohorts are representative because within each we achieved theme saturation (repetition of input). ${ }^{57}$

\section{Experts" Perspectives on NGTS Panels}

How NGTS Panels May Be Used: To illustrate potential NGTS uses, experts described 4 categories of targets included in an NGTS panel (Table 2). Three categories group individual targets based on the degree of proven significance in a specific cancer ("established" or "novel") or across cancers ("pan-cancer"). The fourth, integrative category incorporates multiple targets into one integrated set, enhancing the multifaceted understanding of a patient's tumor. Each category may serve multiple purposes. Experts uniformly described some purposes as clinical or research, whereas their 
Coverage Policy for Tumor Sequencing

Table 2 Clinical Expert Perspectives: Categories of Sequencing Targets Included in NextGeneration Tumor Sequencing Panels and Corresponding Uses

\begin{tabular}{|c|c|c|c|}
\hline Target Category ${ }^{a}$ & Description & How It May Be Used & Type of Use \\
\hline \multirow[t]{3}{*}{ Established targets } & \multirow{3}{*}{$\begin{array}{l}\text { Standard-of-care alterations: } \\
\text { proven validity and } \\
\text { utility for specific cancers } \\
\text { acknowledged by guidelines } \\
\text { and/or covered by payers }\end{array}$} & $\begin{array}{l}\text { Guide the use of a targeted therapy } \\
\text { approved for specific cancer (predictive } \\
\text { targets) }\end{array}$ & Clinical \\
\hline & & $\begin{array}{l}\text { Inform prognostication (prognostic } \\
\text { targets) }\end{array}$ & Clinical \\
\hline & & $\begin{array}{l}\text { Match a patient to a biomarker-driven } \\
\text { clinical trial of a novel drug for an } \\
\text { established target }\end{array}$ & Research \\
\hline \multirow[t]{3}{*}{ Novel targets } & \multirow{3}{*}{$\begin{array}{l}\text { Alterations with known or } \\
\text { suspected, but less proven } \\
\text { validity and/or utility, or } \\
\text { new alterations for known } \\
\text { tumor suppressor genes with } \\
\text { existing targeted therapies }\end{array}$} & $\begin{array}{l}\text { Guide the use of targeted therapy if } \\
\text { available for established variant of } \\
\text { same gene }\end{array}$ & Clinical or research \\
\hline & & $\begin{array}{l}\text { Match patients to biomarker-driven } \\
\text { clinical trials, if available }\end{array}$ & Research \\
\hline & & Inform genomic and drug discovery & Research \\
\hline Pan-cancer targets & $\begin{array}{l}\text { Alterations with established } \\
\text { validity and utility in another } \\
\text { cancer }\end{array}$ & $\begin{array}{l}\text { Guide the use of an approved targeted } \\
\text { therapy based on the target/drug } \\
\text { model from another cancer }\end{array}$ & Clinical or research \\
\hline \multirow[t]{3}{*}{ All of the above } & \multirow{3}{*}{$\begin{array}{l}\text { Enhanced understanding of } \\
\text { a patient's tumor }\end{array}$} & Assess tumor heterogeneity & Clinical or research \\
\hline & & $\begin{array}{l}\text { Determine tumor pathways (eg, } \\
\text { resistance to therapies) }\end{array}$ & Clinical or research \\
\hline & & $\begin{array}{l}\text { Assess temporal tumor behavior and } \\
\text { evolution during treatment (via repeat } \\
\text { monitoring) }\end{array}$ & Clinical or research \\
\hline
\end{tabular}

aTumor genetic or molecular alterations and biomarkers interrogated by next-generation sequencing panels.

designation of other uses (eg, pan-cancer applications) varied: some considered it research activity and others considered it clinical practice.

Similarly, experts' reports varied regarding the settings in which their institutions use NGTS. Some use it in research settings only. Others describe a "patient care setting," which is a hybrid environment that has elements of both clinical (use of a Clinical Laboratory Improvement Amendments laboratory; routine tumor sequencing for specific cancers; funded by internal, institutional budgets, billed to payers for reimbursement, or billed to the patient) and research practices (conducted under an IRB approval; results are used for both standard-of-care and research purposes, including clinical trial enrollment).

\section{Unique Features of NGTS Panels: Expert} participants described distinguishing NGTS features and potential benefits that may transform oncology research and practice (Table 3, available online, in this article, at JNCCN.org). Because NGTS simultaneously interrogates large numbers of established and novel targets, it enables concurrent clinical and research activities with unprecedented efficiency because of optimized use of tumor tissue and returning results in a clinically relevant time frame. Conversely, current one-target-at-a-time testing may take up to 6 weeks or exhaust precious biopsy specimen on the first test. This limits patients' therapeutic choices - standard of care or experimental—or imposes risks, delays, and costs of a repeat biopsy. Experts remarked that NGTS potentiates the integration of standard of care and research for one patient in a truly patient-centric fashion, conferring current benefit from identifying established biomarkers, along with potential future benefit through identifying novel targets that may guide future treatments, as evidence expands.

Experts commented that NGTS benefits must yet be proven, but conventional clinical research methods used for single target/single drug trials are infeasible and may be obsolete in the era of NGTS. There was consensus that the ability to comprehensively categorize tumor genotypes allows for novel enrichment designs in clinical trials and may also enable in silico models simulating a tumor's reaction to therapy. The expert cohort believed that NGTS 
Trosman et al

necessitates development of new clinical research methods, such as $\mathrm{N}$-of-One, basket multicancer and/or multitarget/agent studies, and "big data" approaches.

\section{Payers' Perspectives on NGTS Panels}

Of the interviewed payers, $80 \%$ agreed that NGTS has substantial potential to benefit patients and transform cancer care. However, all payers reported one or more challenges to issuing a positive coverage policy for NGTS, with key challenges categorized as follows and in Table 4.

Not Fitting Definitions of "Medically Necessary" and "Experimental/Investigational": Payers must determine that a technology is "medically necessary" and not "experimental/investigational" to grant coverage; $80 \%$ of payers stated one or more reasons why NGTS does not fit these concepts. Additionally, $70 \%$ commented that although NGTS panels include medically necessary targets, inclusion of any novel targets deems the entire panel experimental/ investigational. They explained that coverage may signal endorsement of novel targets and related offlabel therapy use. However, $30 \%$ noted that inclusion of novel targets may not preclude NGTS coverage if they are labeled unvalidated and associated treatments are not submitted for reimbursement. They also may be willing to support NGTS for cancer research, a new direction for their organizations.

\section{Table 4 Payer Perspectives: Current Challenges to Developing Coverage Policy for NGTS Panels}

\begin{tabular}{|c|c|c|c|}
\hline Challenge Category & $\begin{array}{l}\% \text { of Payers } \\
\text { Noting at Least } \\
\text { One Challenge } \\
(n=10)\end{array}$ & Description of Specific Challenges & $\begin{array}{l}\% \text { of Payers Noting } \\
\text { a Specific Challenge } \\
(n=10)\end{array}$ \\
\hline \multirow{4}{*}{$\begin{array}{l}\text { NGTS does not fit the } \\
\text { definition of "medically } \\
\text { necessary" and "experimental/ } \\
\text { investigational" }\end{array}$} & \multirow[t]{4}{*}{$80 \%$} & $\begin{array}{l}\text { Novel targets and research activities } \\
\text { informed by NGTS deem the entire } \\
\text { panel "experimental/investigation" }\end{array}$ & $70 \%$ \\
\hline & & $\begin{array}{l}\text { Pan-cancer applications are really just } \\
\text { the use of off-label approaches and } \\
\text { are experimental/investigational }\end{array}$ & $60 \%$ \\
\hline & & $\begin{array}{l}\text { Efficiency of testing does not quality } \\
\text { as medically necessary }\end{array}$ & $40 \%$ \\
\hline & & $\begin{array}{l}\text { Future utility and benefit cannot be } \\
\text { determined as medically necessary }\end{array}$ & $50 \%$ \\
\hline \multirow{3}{*}{$\begin{array}{l}\text { Misalignment with "single } \\
\text { test/single result" approach to } \\
\text { coverage }\end{array}$} & \multirow[t]{3}{*}{$70 \%$} & $\begin{array}{l}\text { Considering NGTS a bundle of } \\
\text { targets }\end{array}$ & $70 \%$ \\
\hline & & $\begin{array}{l}\text { No precedent to evaluate integrative } \\
\text { benefits of NGTS }\end{array}$ & $50 \%$ \\
\hline & & $\begin{array}{l}\text { Bioinformatics must be considered as } \\
\text { its own diagnostic, with validity and } \\
\text { accuracy; no precedent to pay for it } \\
\text { separately }\end{array}$ & $60 \%$ \\
\hline \multirow{3}{*}{$\begin{array}{l}\text { Evidence methods proposed } \\
\text { for NGTS do not fit payers' } \\
\text { evidentiary standards }\end{array}$} & \multirow[t]{3}{*}{$70 \%$} & $\begin{array}{l}\text { Large correlative studies are still } \\
\text { required }\end{array}$ & $70 \%$ \\
\hline & & $\begin{array}{l}\text { Skepticism and lack of experience } \\
\text { with new study methodologies (eg, } \\
\mathrm{N} \text {-of-One, basket studies, in silico } \\
\text { modeling, data pooling) }\end{array}$ & $70 \%$ \\
\hline & & $\begin{array}{l}\text { Pan-cancer evidence must be as } \\
\text { extensive as initial indications }\end{array}$ & $30 \%$ \\
\hline \multirow[t]{3}{*}{$\begin{array}{l}\text { Concerns about adoption and } \\
\text { implementation of NGTS in } \\
\text { oncology care }\end{array}$} & \multirow[t]{3}{*}{$50 \%$} & $\begin{array}{l}\text { Departure from standard care } \\
\text { protocols because of increased } \\
\text { personalization; increases care } \\
\text { variability and reduces decision } \\
\text { reproducibility }\end{array}$ & $50 \%$ \\
\hline & & $\begin{array}{l}\text { Lacking infrastructure for } \\
\text { implementation and care delivery }\end{array}$ & $30 \%$ \\
\hline & & $\begin{array}{l}\text { Lack of transparency on how NGTS is } \\
\text { implemented and used }\end{array}$ & $40 \%$ \\
\hline
\end{tabular}

Abbreviation: NGTS, next-generation tumor sequencing. 
Although payers regarded NGTS pan-cancer application a "reasonable hypothesis," 60\% considered it investigational. They will not cover it without outcomes evidence in each cancer, concerned that NGTS will dramatically increase off-label drug use. However, 40\% considered the pan-cancer NGTS application beneficial, because it provides rationale for selected off-label drug use, which is already common in oncology. Payers may not formally cover pan-cancer therapies, but could continue payment on exception bases. However, they also expressed concern that NGTS will drive higher exception volume, and called for establishing consistent criteria for pan-cancer uses.

Although payers agreed with several other NGTS advantages, such as efficiency of testing and future benefit from sequencing, these lack precedent for coverage and do not fall under a benefit that could be determined medically necessary. Payers expressed difficulty with evaluating how these will directly benefit patients and improve outcomes.

Misalignment With Single Test/Single Result Approach to Coverage: Seventy percent of payers will evaluate each target included in an NGTS panel individually, using single test/single result approaches. Although acknowledging this daunting, they will not evaluate NGTS as one package, because they do not perceive the integrated benefit of NGTS, such as comprehensive tumor characterization. The other 30\% would consider NGTS as one test for coverage, but noted the lack of methodology and few or no precedents for evaluating integrative NGTS benefits.

Payers also stated absent precedent for evaluating the bioinformatics component of NGTS. Sixty percent recognized the importance of this component, and acknowledged it may warrant higher reimbursement for NGTS or a separate payment. Consequently, payers considered it necessary to evaluate bioinformatics for accuracy (eg, sensitivity and specificity) similarly to diagnostic tests. Yet, payers have no methodologies for evaluating bioinformatics and whether and how to establish related coverage policies.

Evidence Methods Proposed for NGTS Do Not Fit Payers' Evidentiary Standards: When evaluating a diagnostic, $100 \%$ of payers require evidence of analytic validity, clinical validity, and clinical utility (including outcomes from treatments guided by the diagnostic), and all of them will apply these requirements to NGTS coverage. Regarding health outcomes, $70 \%$ realize that phase III randomized control trials are not feasible for the many-tomany target-drug combinations, and may accept lower levels of evidence, especially for pan-cancer applications already approved in one cancer. The other $30 \%$ will require the same phase III evidence as for the initially approved indication. Separately, $30 \%$ acknowledged that integrative features of NGTS, such as tumor pathway characterization, require novel study methods. Illustratively, one payer noted, "Sequencing is far beyond conventional tests, and we may need to get out of the box." However, $70 \%$ were skeptical about new study models but expressed interest in better understanding them.

Adoption and Care Delivery Concerns: Eighty percent of payers believed that implementing NGTS in practice will face difficulties, and expressed concerns that these difficulties will preclude the promised advantages. Fifty percent expressed sufficient concerns about NGTS adoption and implementation that will preclude their ability to issue positive coverage. Although appreciating the potential benefit of increased personalization facilitated by NGTS, $50 \%$ were concerned that this will drive departure from the current trend toward standardization and the use of consistent treatment pathways. They noted that NGTS will lead oncologists back to the art of decision-making, increasing variability of care and outcomes.

Before coverage, $30 \%$ of payers want to see an indication that laboratories and cancer centers offering NGTS develop the necessary infrastructure for end-toend delivery, beyond buying a sequencer or ordering a panel. This may include capturing NGTS results in electronic medical records, preparing physicians to use results in care, and establishing care processes, such as future recontacting of patients. Of specific concern was the establishment of the NGTS infrastructure and care delivery processes in community oncology, to avoid overwhelming community oncologists with this new technology, while ensuring patient access beyond academic centers. Forty percent of payers want to establish more transparency in this field, including providers' transparency to payers and patients on how NGTS is implemented, validated, used, and explained, not oversold, to patients. 
Trosman et al

\section{Discussion}

Our study identified private payers' considerations and challenges for coverage of NGTS panels. To our knowledge, this is the first study to directly interview US payers on this topic. We discovered that although payers consider NGTS benefits a compelling hypothesis, NGTS conflicts with the concept of medical necessity, does not fit the current single test/single result coverage framework, and presents adoption concerns that must addressed before coverage. Payers generally do not consider new clinical evidence methods proposed for NGTS acceptable for coverage.

Our findings indicate that some challenges are common between NGTS and other novel diagnostic tests, and could potentially be addressed within the existing coverage and evidence framework. However, other challenges are unique to NGTS and may be disruptive to the current coverage and evidence framework. Both types of challenges are discussed and an approach for addressing the challenges unique to NGTS is suggested.

Evidentiary challenges to coverage are not unique to NGTS and include absent evidence standards and a dearth of clinical utility proof. ${ }^{12,47,58-61}$ However, NGTS may exacerbate these challenges, ${ }^{8,62}$ partly, as we found, because no methodology exists for evaluating its unique features (eg, integrative features) within current evidence assessment frameworks created for single test/single result assays. To our knowledge, to date, only one evidence evaluation group undertook an assessment that included an NGTS unique feature-pathway characterization-commenting on difficulty of assessing this feature and related evidence. ${ }^{63}$ Although evidence evaluation groups call for new research methods for diagnostics (eg, observational studies, big data approaches), ${ }^{62,64-66}$ they have not included methods potentially suited for NGTS evidence (eg, $\mathrm{N}$-of-One, basket pan-cancer studies). Some evidence evaluation groups deem these methods immature, ${ }^{63}$ echoing payers in our study.

Evidentiary challenges, although substantial, could be conceivably addressed within the existing evidence and coverage framework through agreeing on novel research methods and developing corresponding evidence. However, other NGTS challenges are inherently disruptive to the existing coverage and evidence approach. Currently, for single test/single result assays, a linear trajectory to a "yes/no" medical necessity and coverage decision exists. Despite evidentiary challenges, arguably any such assay, if worthwhile, can follow this trajectory as its evidence base is developed, until determined sufficient and related benefit medically necessary. The assay is covered thereafter. All currently covered tests underwent this path. However, NGTS does not fit this trajectory. As indicated by our findings, because important NGTS benefits are predicated on inclusion of novel (along with established) targets, the panels will be deemed experimental/investigational and not medically necessary. The inclusion of novel targets is not a temporary, but a permanent, NGTS feature: as evidence is developed for novel targets and they become established, other novel targets will emerge and be included. Therefore, no new evidence may deem the entire panel medically necessary.

Our findings indicate another disruptive aspect of NGTS: it facilitates the transformation of oncology toward a model that is highly personalized and integrates research and standard care. Although this model holds substantial promise, it may run contrary to current coverage/reimbursement and clinical practice trends. Two examples illustrate this disruptive challenge.

First, NGTS supports integration of all care for one patient, both standard and experimental, facilitating choice of existing treatments and determination of trial eligibility in a clinically relevant time frame. This may substantially increase patient therapeutic options, and advance patient-centric oncology. However, it counters the current model of financing patient care, which requires fragmentation of standard-of-care versus experimental activities for reimbursement purposes. Experimental activities are further fragmented, because pharmaceutical trial sponsors require single-marker testing and may not finance NGTS as a shared utility. To address this issue, MD Anderson developed a sophisticated sequential multistep tumor sequencing process, which separates reimbursable and investigational sequencing. ${ }^{4}$ However, this experience of the world's largest cancer center may not be easily repeated in other centers, and the impact on costs and result turnaround time must be assessed.

Second, the increased personalization of patient care facilitated by NGTS, although being the premise of precision oncology, may counter the 
existing trends toward care decision standardization and treatment pathway adoption. Integrative, multitarget NGTS features, such as comprehensive tumor characterization, are not yet conducive to being incorporated into a treatment pathway or a decision algorithm, potentially causing increased variation in decisions and treatments. Practice variation is considered a culprit in the current health care environment striving for standardization.

Our findings raise a critical question for oncology stakeholders: do we redefine NGTS to fit the coverage and evidence framework, or do we redefine the coverage and evidence framework to fit NGTS? The former option would require limiting NGTS disruptive features, such as inclusion of novel targets or pan-cancer applications. Although it may diminish the potential for transformative benefits, it will have important merits, such as reducing the risk and health care costs, which is highly compelling in the current oncology environment. The latter option is undoubtedly more uncertain and complex, but provides a potential for realizing arguably unprecedented benefits. This option requires a 3 -pronged collaborative approach across stakeholders: (1) explicitly define disruptive features of NGTS, (2) adjust the evidentiary framework, including methods of evidence research and approaches to evidence evaluation, and (3) adjust the coverage and reimbursement framework to align with the evidentiary framework and allow incorporation of NGTS advantages.

Addressing NGTS-related challenges may require that payers, clinicians, clinical researchers, and laboratory-based scientists acknowledge and adapt to the dynamic and rapidly evolving interface between the clinical and research realms in oncology, facilitated by NGTS - an interface that must not be a barrier but rather a new arena of long-awaited, immense promise.

This study had several limitations. We used a small payer cohort that did not allow statistical power and did not include public payers, which are important coverage decision-makers. This was mitigated by the fact that the included payers cover a third of the US population, and 7 are the top-10 largest plans whose policies influence other private and public payers. As an exploratory effort, our study identified key issues but did not provide an exhaustive account of challenges that must be addressed, nor did it examine specific issues in detail. Future studies should conduct deeper examination of these challenges with broader and larger sets of stakeholders to allow the crafting of possible solutions.

\section{Conclusions}

Payers perceive that NGTS panels hold significant promise but, in their current form, pose disruptive challenges to coverage policy framework. Proactive multidisciplinary efforts to define the direction for NGTS development, evidence generation, and incorporation into coverage policy are necessary to realize its promise and provide patient access.

\section{References}

1. Gazdar AF, Minna JD. Precision medicine for cancer patients: lessons learned and the path forward. J Natl Cancer Inst 2013;105:1262-1263.

2. Ross JS. Cancer biomarkers, companion diagnostics and personalized oncology. Biomark Med 2011;5:277-279.

3. Garraway LA, Verweij J, Ballman KV. Precision oncology: an overview. J Clin Oncol 2013;31:1803-1805.

4. Mendelsohn J. Personalizing oncology: perspectives and prospects. J Clin Oncol 2013;31:1904-1911.

5. Boguski MS, Arnaout R, Hill C. Customized care 2020: how medical sequencing and network biology will enable personalized medicine. F1000 Biol Rep 2009;1:73.

6. Li T, Kung HJ, Mack PC, et al. Genotyping and genomic profiling of nonsmall-cell lung cancer: implications for current and future therapies. J Clin Oncol 2013;31:1039-1049.

7. Dienstmann R, Rodon J, Barretina J, et al. Genomic medicine frontier in human solid tumors: prospects and challenges. J Clin Oncol 2013;31:18741884 .

8. Bombard Y, Bach PB, Offit K. Translating genomics in cancer care. J Natl Compr Canc Netw 2013;11:1343-1353.

9. Ellis M. Genomic analysis of breast cancer heralds a changing treatment paradigm. J Natl Compr Canc Netw 2014;12(5 Suppl):750-752.

10. MacConaill LE. Existing and emerging technologies for tumor genomic profiling. J Clin Oncol 2013;31:1815-1824.

11. Kim RY, Xu H, Myllykangas $S$, et al. Genetic-based biomarkers and nextgeneration sequencing: the future of personalized care in colorectal cancer. Per Med 2011;8:331-345.

12. Korf BR, Rehm HL. New approaches to molecular diagnosis. JAMA 2013;309:1511-1521.

13. Deeb KK, Sram JP, Gao H, et al. Multigene assays in metastatic colorectal cancer. J Natl Compr Canc Netw 2013;11(Suppl 4):S9-17.

14. Schrijver I, Aziz N, Farkas DH, et al. Opportunities and challenges associated with clinical diagnostic genome sequencing: a report of the Association for Molecular Pathology. J Mol Diagn 2012;14:525-540.

15. Manolio TA, Chisholm RL, Ozenberger B, et al. Implementing genomic medicine in the clinic: the future is here. Genet Med 2013;15:258-267.

16. Johansen Taber KA, Dickinson BD, Wilson M. The promise and challenges of next-generation genome sequencing for clinical care. JAMA Intern Med 2014;174:275-280.

17. Welch JS, Westervelt $P$, Ding L, et al. Use of whole-genome sequencing to diagnose a cryptic fusion oncogene. JAMA 2011;305:1577-1584.

18. Link DC, Schuettpelz LG, Shen D, et al. Identification of a novel TP53 cancer susceptibility mutation through whole-genome sequencing of a patient with therapy-related AML. JAMA 2011;305:1568-1576.

19. Perkel J. Finding the true $\$ 1000$ genome. Biotechniques $2013 ; 54: 71-74$.

20. DeFrancesco L. Life Technologies promises $\$ 1,000$ genome. Nat Biotechnol 2012;30:126. 
Trosman et al

21. Bonetta L. Whole-genome sequencing breaks the cost barrier. Cell 2010;141:917-919.

22. Caulfield T, Evans J, McGuire A, et al. Reflections on the cost of "low-cost" whole genome sequencing: framing the health policy debate. PLoS Biol 2013;11:e1001699.

23. Ettinger DS, Wood DE, Akerley W, et al. NCCN Clinical Practice Guidelines in Oncology: Non-Small Cell Lung Cancer. Version 4.2015. Available at: NCCN.org. Accessed July 13, 2014

24. Lindeman NI, Cagle PT, Beasley MB, et al. Molecular testing guideline for selection of lung cancer patients for EGFR and ALK tyrosine kinase inhibitors: guideline from the College of American Pathologists, International Association for the Study of Lung Cancer, and Association for Molecular Pathology. Arch Pathol Lab Med 2013;137:828-860.

25. GPS@WUSTL. Genomics and Pathology Services. Washigton University School of Medicine in St. Louis Web site. Available at: http://gps.wustl. edu/. Accessed July 13, 2014.

26. Foundation Medicine, FoundationOne. http://foundationone.com/. Accessed July 13, 2014.

27. Molecular Intelligence. Caris Life Sciences Web site. Available at: http:// www.carislifesciences.com/next-generation-sequencing-cancer. Accessed July 13, 2014.

28. Hartocollis A. Cancer centers racing to map patients' genes. The New York Times. April 21, 2013. Available at: http://www.nytimes.com/2013/04/22/ health/patients-genes-seen-as-future-of-cancer-care.html?pagewanted=all. Accessed July 13, 2014.

29. Eisenberg A. Variations on a gene, and tools to find them. The New York Times. April 27, 2013. Available at: http://www.nytimes.com/2013/04/28/ business/in-cancer-treatment-new-dna-tools.html. Accessed July 13, 2014.

30. Winslow R. Sloan Kettering gets $\$ 100$ million gift. The Wall Street Journal. May 19, 2014. Available at: http://www.wsj.com/articles/SB100 01424052702304652804579572111166009066 . Accessed July 13, 2014.

31. Collins FS. Francis Collins says medicine in the future will be tailored to your genes. The Wall Street Journal. July 7, 2014. Available at: http:// www.wsj.com/articles/francis-collins-says-medicine-in-the-future-will-betailored-to-your-genes-1404763139. Accessed July 13, 2014.

32. Clinical Policy Bulletin: Tumor Markers. Number 0352. Aetna Web site. Available at: http://www.aetna.com/cpb/medical/data/300_399/0352.html. Accessed July 13, 2014.

33. Anthem Medical Policy: Molecular Profiling for the Evaluation of Malignant Tumors. Policy \# GENE.00025. Available at: http://www. anthem.com/medicalpolicies/policies/mp_pw_c150728.htm. Accessed July $13,2014$.

34. Florida Blue. Medical coverage guidelines: genetic testing. 05-82000-28. Available at: http://mcgs.bcbsfl.com/. Accessed July 13, 2014.

35. Premera Blue Cross Medical Policy: Molecular panel testing of cancers to identify targeted therapies. Available at: https:/www.premera.com/ medicalpolicies/CMI_160067.htm. Accessed July 13, 2014.

36. Heger M. Official discusses Wash U's successful strategy in developing a reimbursable NGS cancer test. Genomeweb Web site. Available at: https:// www.genomeweb.com/sequencing/official-discusses-wash-us-successfulstrategy-developing-reimbursable-ngs-cance. Accessed June 18, 2014.

37. Berger A, Olson S. The economics of genomic medicine: workshop summary. Washington, DC: The National Academies Press; 2013.

38. United States. Department of Health and Human Services. Secretary's Advisory Committee on Genetics, Health and Society [SACGHS]. Coverage and Reimbursement of Genetic Tests and Services: Report of the Secretary's Advisory Committee on Genetics, Health, and Society. Washington, DC: Department of Health and Human Services; 2006.

39. Ward E, Halpern M, Schrag N, et al. Association of insurance with cancer care utilization and outcomes. CA Cancer J Clin 2008;58:9-31.

40. Engstrom PF, Bloom MG, Demetri GD, et al. NCCN molecular testing white paper: effectiveness, efficiency, and reimbursement. J Natl Compr Canc Netw 2011;9(Suppl 6):S1-16

41. Olson $S$, Beachy $S$, Giammaria $C$, et al. Integrating large-scale genomic information into clinical practice: workshop summary. Washington, DC: The National Academies Press; 2012.

42. Employee Benefit Resaerch Institute. Sources of health insurance and characteristics of the uninsured: analysis of the March 2013 Current
Population Survey. Available at: http://www.ebri.org/pdf/briefspdf/EBRI IB_09-13.No390.Sources1.pdf. Accessed July 13, 2014.

43. Trosman JR, Van Bebber SL, Phillips KA. Coverage policy development for personalized medicine: private payer perspectives on developing policy for the 21-gene assay. J Oncol Pract 2010;6:238-242.

44. Van Bebber SL, Trosman JR, Liang SY, et al. Capacity building for assessing new technologies: approaches to examining personalized medicine in practice. Per Med 2010;7:427-439.

45. Trosman JR, Van Bebber SL, Phillips KA. Health technology assessment and private payers' coverage of personalized medicine. J Oncol Pract 2011;7(3 Suppl):18s-24s.

46. Weldon CB, Trosman JR, Gradishar WJ, et al. Barriers to the use of personalized medicine in breast cancer. J Oncol Pract 2012;8:e24-31.

47. Trosman JR, Weldon CB, Schink JC, et al. What do providers, payers and patients need from comparative effectiveness research on diagnostics? The case of HER2/Neu testing in breast cancer. J Comp Eff Res 2013;2:461477.

48. Ritchie J, Lewis J. Qualitative research practice: a guide for social science students and researchers. London, England: Sage Publications; 2003.

49. Meyer J. Qualitative research in health care. Using qualitative methods in health related action research. BMJ 2000;320:178-181.

50. Patton MQ. Qualitative research and evaluation methods. 3rd ed. Thousand Oaks, CA: Sage Publications; 2002.

51. Deverka PA. Pharmacogenomics, evidence, and the role of payers. Public Health Genomics 2009;12:149-157.

52. Bombard Y, Rozmovits L, Trudeau M, et al. Access to personalized medicine: factors influencing the use and value of gene expression profiling in breast cancer treatment. Curr Oncol 2014;21:e426-433.

53. Husereau D, Marshall DA, Levy AR, et al. Health technology assessment and personalized medicine: are economic evaluation guidelines sufficient to support decision making? Int J Technol Assess Health Care 2014;30:179187.

54. McGowan ML, Settersten RA Jr, Juengst ET, et al. Integrating genomics into clinical oncology: ethical and social challenges from proponents of personalized medicine. Urol Oncol 2014;32:187-192.

55. McGuire AL, Robinson JO, Ramoni RB, et al. Returning genetic research results: study type matters. Per Med 2013;10:27-34.

56. Miller FA, Hayeems RZ, Bytautas JP, et al. Testing personalized medicine: patient and physician expectations of next-generation genomic sequencing in late-stage cancer care. Eur J Hum Genet 2014;22:391-395.

57. Pope C, Mays N. Qualitative research in health care. 3rd ed. Oxford, UK: Blackwell Publishing Ltd; 2006.

58. Febbo PG, Ladanyi M, Aldape KD, et al. NCCN task force report: evaluating the clinical utility of tumor markers in oncology. J Natl Compr Canc Netw 2011;9(Suppl 5):S1-32; quiz S33

59. Evans JP, Khoury MJ. The arrival of genomic medicine to the clinic is only the beginning of the journey. Genet Med 2013;15:268-269.

60. Garrison LP Jr, Neumann PJ, Radensky P, et al. A flexible approach to evidentiary standards for comparative effectiveness research. Health Aff (Millwood) 2010;29:1812-1817.

61. Deverka PA, Schully SD, Ishibe N, et al. Stakeholder assessment of the evidence for cancer genomic tests: insights from three case studies. Genet Med 2012;14:656-662.

62. Veenstra DL, Piper M, Haddow JE, et al. Improving the efficiency and relevance of evidence-based recommendations in the era of whole-genome sequencing: an EGAPP methods update. Genet Med 2013;15:14-24.

63. Blue Cross Blue Shield Association Technology Evaluation Center; Kaiser Foundatio Health Plan; Southern California Permanente Medical Group. Special report: multiple molecular testing of cancers to identify targeted therapies. Chicago, IL: Blue Cross and Blue Shield Association; 2013.

64. Berg JS, Khoury MJ, Evans JP. Deploying whole genome sequencing in clinical practice and public health: meeting the challenge one bin at a time. Genet Med 2011;13:499-504.

65. Goddard KA, Whitlock EP, Berg JS, et al. Description and pilot results from a novel method for evaluating return of incidental findings from nextgeneration sequencing technologies. Genet Med 2013;15:721-728.

66. Dotson WD, Douglas MP, Kolor K, et al. Prioritizing genomic applications for action by level of evidence: a horizon-scanning method. Clin Pharmacol Ther 2014;95:394-402. 